ÉGYPTE monde arabe

\section{Égypte/Monde arabe}

12-13 | 1993

Une économie en transition

\title{
La « passivité » politique des coptes : essai d'explication
}

\author{
Al-Ahrâm, 2 juin 1992
}

Yunan Labib Rizq

Traducteur : Heba al-Fernawany

\section{(2) OpenEdition}

12 Journals

Édition électronique

URL : https://journals.openedition.org/ema/1285

DOI : 10.4000/ema.1285

ISSN : 2090-7273

Éditeur

CEDEJ - Centre d'études et de documentation économiques juridiques et sociales

Édition imprimée

Date de publication : 31 mars 1993

Pagination : 259-261

ISSN : 1110-5097

\section{Référence électronique}

Yunan Labib Rizq, «La « passivité » politique des coptes : essai d'explication », Égypte/Monde arabe [En ligne], 12-13 | 1993, mis en ligne le 08 juillet 2008, consulté le 07 juillet 2022. URL : http:// journals.openedition.org/ema/1285; DOI : https://doi.org/10.4000/ema.1285

Ce document a été généré automatiquement le 7 juillet 2022.

Tous droits réservés 


\title{
La « passivité » politique des coptes : essai d'explication
}

\author{
Al-Ahrâm, 2 juin 1992 \\ Yunan Labib Rizq \\ Traduction : Heba al-Fernawany
}

1 La «passivité " politique des coptes a fait l'objet, ces dernières années, d'un discours récurrent : cela nécessite une explication ou, du moins, une tentative d'explication. En fait, ceux qui reprennent ce discours à leur compte font allusion au retrait des coptes de la fonction publique et, plus généralement, de la vie politique au cours de ces dernières décennies. Ce discours reflète donc, dans une certaine mesure, la réalité. L'absence, à la tête des principaux partis politiques, de personnalités coptes notables en témoigne ; seules exceptions : le Parti Wafd, pour des raisons historiques, et le Parti du Rassemblement.

2 Autre signe : la surprise que manifestent les Égyptiens lorsqu'ils entendent pour la première fois le nom de telle ou telle personnalité venant d'être nommée à un poste ministériel : le choix, comme c'était le cas pour le ministère de 'Atif Sidqi, repose sur des critères personnels ou... technocratiques !

3 Troisième signe: la manière dont on procède pour assurer un semblant de représentation copte dans les diverses instances législatives, qu'il s'agisse de l'Assemblée du Peuple ou du Conseil consultatif: on sélectionne des personnalités coptes qui, pour occuper d'éminentes fonctions, ne sont pas nécessairement pour autant des personnes publiques. Ou on choisit certains éléments des partis d'opposition. Le phénomène s'est produit à deux reprises : la première fois, on a choisi un des pôles du Parti du Rassemblement, ce qui a entraîné un conflit entre lui et son parti ; la seconde fois, ce fut un membre du bureau du Wafd, ce qui a abouti aux mêmes conséquences. En réalité, rares sont les coptes qui accèdent au parlement par voie électorale. 
4 Le discours sur la passivité - ou le «négativisme »- des coptes est donc fondé en apparence. Il est cependant nécessaire, avant d'essayer de l'expliciter, d'éclairer quelques aspects du problème :

1. la passivité actuelle en matière d'activité politique ne concerne pas seulement les coptes mais la population dans son ensemble, ceci pour des raisons d'appartenance à tel groupe social ou à tel sexe ;

2. la passivité de diverses catégories de la population n'est pas une fatalité ou un trait inné; c'est une donnée résultant de variables sur lesquelles ces catégories peuvent parfois influer mais qui sont le plus souvent incontrôlables ;

3. le sentiment d'un retrait actuel des coptes est lié au rôle qu'ils jouaient avant 1952 ; par la suite, ce rôle s'est considérablement affaibli.

5 Comment les coptes intervenaient-ils dans la vie politique avant 1952? Le mouvement national était leur première voie d'accès. Les Égyptiens avaient pris conscience, à l'époque, que l'unité nationale était un de leurs atouts essentiels; ils tenaient à préserver cette unité, à telle enseigne que lors de la révolution de 1919 et au cours des années suivantes, ils parlaient d'« union sacrée »; aucune force n'était susceptible d'y porter atteinte.

6 Seconde voie : la société civile. La société délaissait ses oripeaux religieux au profit d'une apparence civile reflétant la vie politique. La religiosité qui subsistait au sein du Parti national avant la première guerre mondiale disparut tout à fait du Wafd ; de plus, les Frères musulmans, considérés comme un groupe qui prônait la résistance à la société civile, ne vit s'accroître son rôle qu'à la fin des années 40 et au début des années 50. La prééminence de la société civile se reflétait dans la communauté copte : cela était devenu manifeste dans la lutte entre le clergé et les partisans de la laïcité dans le dernier quart du XIX ${ }^{e}$ siècle et au début du XX ${ }^{e}$, notamment après la création du majlis milli et le contrôle laïc des biens de l'Église.

7 Troisième voie : le statut social. Les grands propriétaires terriens et l'élite cultivée (les « effendis ») constituaient, avant 1952, la colonne vertébrale de l'action politique. Les coptes représentaient un pourcentage non négligeable de cette couche sociale. Aussi pouvait-on penser que, logiquement, leur rôle irait croissant. Or, les événements des années 50 barrèrent la route définitivement non seulement aux coptes mais à l'ensemble des élites politiques.

8 Le mouvement national tel qu'il avait été conçu au départ prit fin avec le départ des Anglais. Ce fut également la fin, lors des nationalisations, de la classe des propriétaires et des effendis. Des composantes d'avant 1952, il ne restait plus que la société civile. Mais la société civile d'avant 1952 était l'aboutissement d'une longue évolution historique, tandis que celle d'après reposait sur la puissance de l'État, ce dont témoigne l'interdiction des mouvements religieux à l'époque.

9 Passons à la fin des années 70, caractérisées par le retour d'un pluripartisme que les années 80 allaient confirmer. L'on pouvait penser que cela favoriserait la participation des différentes composantes de la société - y compris les coptes - à la vie politique. Pourtant, au moins en ce qui concerne ces derniers, la réaction a été très modeste. La raison en incombe à divers facteurs.

10 Le parti de la majorité (Parti national démocrate) en est le premier responsable. Outre qu'il n'a pas pris en considération, dans son programme, la question de l'unité nationale, il a favorisé une certaine partie de ses adhérents: la majorité d'entre eux 
étant des personnes intéressées à profiter du pouvoir à quelque titre que ce soit, les rangs du PND se sont grossis de fonctionnaires avides d'accéder à tel ou tel poste et de partisans de l'ouverture économique désireux de protéger leurs intérêts... On trouvait même parmi eux des trafiquants de stupéfiants! Les coptes n'occupent pas une place significative parmi ces derniers...,

11 Du côté de l'opposition, le Parti Wafd a déçu de nombreux coptes après avoir abandonné son rôle traditionnel de gardien de l'unité nationale tout en passant alliance avec les Frères musulmans lors des élections de 1984 : ce geste ne laissait plus guère de place à la présence des coptes en son sein. Quant au Parti du Rassemblement, il continue à compter des coptes parmi ses adhérents, mais le nombre des adhérents a globalement diminué, surtout après les revers successifs essuyés par le socialisme dans la seconde moitié des années 80 , d'autant que tous les coptes ne sont pas socialistes...

12 Sur le plan social, on a vu apparaître, dans les années 70, une classe résultant de la politique d'ouverture économique, qui s'est enrichie par des moyens douteux et dont la fortune est probablement issue de pays conservateurs. Cette classe ayant utilisé la religion comme couverture, il s'en est suivi la constitution d'institutions coptes selon le même procédé. Il y avait peu de chances que les deux ailes se rencontrent pour participer ensemble à la vie politique, comme cela s'est produit avant 1952 avec la classe des grands propriétaires terriens musulmans et coptes.

13 La perturbation qu'a introduite dans le corps social cette classe de nouveaux riches, favorisant par là même le développement du courant religieux, a poussé la société civile copte à déléguer son rôle politique à ses guides religieux, lesquels, de ce fait, occupent une place de plus en plus importante dans la vie politique.

14 Entre une formule partidaire avortée, des changements sociaux adverses, un renoncement des coptes laïcs à leur rôle historique, il était normal que se manifeste chez les coptes une certaine passivité. Ce n'est pas tant l'émergence du phénomène qui nous inquiète, que sa permanence.

\section{INDEX}

Mots-clés : Coptes 